\title{
ON MYXOMA OF THE CHORIONIC VILLI, OR VESICULAR MOLE.
}

\author{
BY THOMAS MORE MADDEN, M.D., F.R.C.S. Ed.; \\ Obstetric Physician, Mater Misericordiæ Hospital, Dublin ; \\ President, Obstetric Section, British Medical Association, \&c., \&c.
}

[Read in the Section of Obstetrics, May 25, 1888.]

THE practical importance of the ætiology of all forms of intra-uterine death, the continued obscurity of their pathology, and the great difficulty of their prevention, may render the following cases and observations on one of the most important of these causes of embryonic destruction of some interest:-

CASE I.-L. D., aged twenty-eight years, the mother of four children, had a miscarriage at the second month, early in December, and was admitted to St. Monica's Ward on April 15th, in a state of extreme anæmia from uterine hæmorrhage, from which she had been suffering ever since the date of the abortion. The day after admission I rapidly expanded the cervical canal with the dilator I recently exhibited to the Academy, so as to allow the introduction of my finger into the uterine cavity, whence I removed a large mass of firmly adherent placental structure, which was found to have undergone vesicular or myxomatous degeneration. The enlarged uterus was then curetted, and subsequently brushed out with Churchill's iodine; the patient was put on large doses of liquor ergotæ, together with tincture of perchloride of iron, under the influence of which the uterus speedily regained its normal size; the hæmorrhage ceased, and within ten days she was enabled to leave the hospital.

The history of this case is very similar to that of another instance of the same disease that $I$ met with some years since, and to the particulars of which I may therefore very briefly refer:-

CASE II.-E. G., aged thirty years; married; eight children; admitted May 9th, suffering from persistent uterine hæmorrhage, which had continued since November last, when she miscarried at the seventh month. On admission she was in a state of great 
exhaustion, and completely blanched from loss of blood. Her pulse was 120, and so feeble as to be almost imperceptible at the wrist; and she complained of tinnitus aurium. The hæmorrhage was now a slight but incessant draining, with occasional gushes of blood on every exertion. Stimulants having been given, the uterus was examined, and found to be considerably enlarged. The os was contracted, but sufficiently dilatable to allow the introduction of a faggot of sea-tangle tents; after which the vagina was securely plugged with sponge. On removing the tents next morning the cavity of the uterus was found occupied by a large hydatidinous mass attached to the fundus. 'The removal of this growth, which filled a small hand-basin, and of a small portion of firmly adherent placenta from which it grew, was attended by considerable hæmorrhage, which was arrested in the ordinary way, and the patient made a rapid recovery.

This case was the first instance that I met with in which a large myxomatous growth was developed from a very small portion of adherent placenta, continuing its abnormal vitality for five months after childbirth, and under circumstances which prevented subsequent impregnation. A fragment of the retained placenta, on examination, proved to be in a state of fatty degeneration.

Importance of the Study of Placental and Embryonic Disease.-The history of all cases of placental disease appears to me deserving of record, since in the comparative paucity of communications on this subject in our "Transactions," we find sufficient evidence that these diseases have even yet attracted less attention than their practical importance demands. It should, perhaps, be here observed that I include vesicular mole amongst placental diseases, inasmuch as, from my own experience and observation, I can confirm the views of those who hold that in such cases the disease generally begins in the placental chorionic villi, and thence the cystic proliferations extend through the intervening tissues into the parenchyma of that structure. The obscurity of their origin, and the difficulty of diagnosis in these cases, have-since the publication, many years ago, of the late Sir James Simpson's memoirs on this subject-been to some extent cleared away by the papers on placental diseases of Dr. Robert Barnes in the "Medico-Chirurgical Transactions," and 
by those of Drs. Graily Hewitt and Braxton Hicks in the "Transactions of the London Obstetrical Society," and above all by the elaborate researches of Virchow, and by Dr. Priestley in his recent work, "On the Pathology of Intra-uterine Death." Notwithstanding all this, however, no subject of equal interest in a practical as well as in a physiological point of view remains in greater obscurity than the diseases of the placenta. It would be superfluous to $d w e l l$ on the importance of this still neglected field of investigation, or to do more than observe that being, as it is, the sole medium of vital communication between the foetus in utero and the mother, any deviation from the normal condition of the placenta by which its development may be arrested and its physiological action impaired or perverted must be of serious consequence either to mother, or to child, or to both.

Various Forms of Placental Disease.-Amongst the diseases of this organ affecting the mother as well as the child are inflammations of the placenta, especially chronic or subacute placentitis, leading to morbid adhesions between the afterbirth and uterus, and occasionally giving rise to the two most serious complications of parturition-viz., post-partum hæmorrhage and inversion of the uterus. Another placental disease of no less importance to the mother than to the child is congestion, sometimes resulting in hæmorrhage or placental apoplexy; whilst amongst the placental diseases which chiefly affect the foetus by impairing or destroying the structural integrity of this organ are odema, atrophy, and hypertrophy of the afterbirth, and the various forms of degeneration-fatty and calcareous; and, above all, that now under consideration-viz., vesicular, or myxomatous, or, as it was formerly termed, hydatidiform degeneration. In my own practice $I$ have now met with five cases of this disease, the infrequency of which appears from the following table:-

\begin{tabular}{|c|c|c|c|}
\hline \multicolumn{2}{|c|}{ Authority } & $\begin{array}{l}\text { Cases admitted into the } \\
\text { Rotunda Hospital }\end{array}$ & $\begin{array}{l}\text { Cases of Hydatidinous } \\
\text { Disease reported }\end{array}$ \\
\hline Illins & - & 16,654 & - \\
\hline rs. Hardy a & M'Clintock & 6,634 & 1 \\
\hline rs. Sinclair ar & ad Johnston & 13,748 & 4 \\
\hline
\end{tabular}


Thus it appears that in 37,036 cases admitted into the Lying-in Hospital, there were only five instances of hydatidiform mole recorded, being in the proportion of 1 in 7,407 cases.

Vesicular or hydatinous disease of the placenta consists in degrneration and abnormal proliferation of the placental chorionic villi, usually following, although occasionally producing, the death of the foetus. In the old "Dublin Obstetrical Transactions" and elsewhere I related several cases of this kind. In most of these the hydatidiform mass was expelled from the uterus in the fifth month. In some instances, however, such growths are expelled earlier, as in a case published by Dr. Moorhead, of Weymouth, in which a hydatidiform ovum was produced at about the tenth week by a woman, aged fifty, who had not had a child for twenty years before. In other cuses it may be much later, as in my second case, also in one related by the late Sir James Simpson, in both of which the patients reckoned themselves gone beyond the full time of utero-gestation; and in another, given by Mr. Ley; of South Molton, in which the woman was supposed by herself and by her medical attendant to have gone the full term of nine months. The symptoms of this disease can at first hardly be distinguished from those of ordinary pregnancy. If, however, in addition to the signs that usually denote the death of the foetus, the patient experiences occasional gushes of water, together with slight hæmorrhage from the uterus, lasting for a short time and recurring at irregular intervals, we may suspect the existence of hydatidiform disease in the placenta of a blighted foetus. The expulsion of these growths from the uterus is generally attended with severe hæmorrhage.

History of this Subject.-At a time when I had more leisure than is now at my disposal, I collected the opinions of many of the older authorities on the character of these growths, and some few of their views thereon may possibly seem to others, as well as to myself, of sufficient interest to warrant their brief recapitulation in this connection.

The first of these theories is that of Hippocrates, who, in the treatise "On Airs, Waters, and Places," ascribes the occurrence of uterine hydatids to the effect of drinking marsh and stagnant 
waters. Dr. Adams, in his learned commentary on the work of Hippocrates, says :- "It may appear singular that hydatids of the womb should be peculiarly prevalent in the case of women that drink unwholesome water from marshes, and yet our author's observation is confirmed by a modern authority, as quoted by Coray:- 'Il a été également prouvé par les observations des modernes, que les fausses grossesses produites par les hydatids sont très-communes dans les pays marécageux où la plupart des habitans ont une constitution lâche, propre à l'affection scorbutique qui y est presque endémique, qu'elles se terminent plus ou moins tard par l'excretion de ces hydatids.' " a

A full account of the ancient doctrines on this subject may be

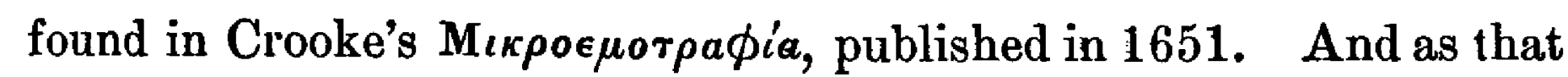
work is not very commonly met with at the present day, I regret that the space at my disposal only suffices for a few lines of quotation from this very curious volume :- "To perfect conception," says our

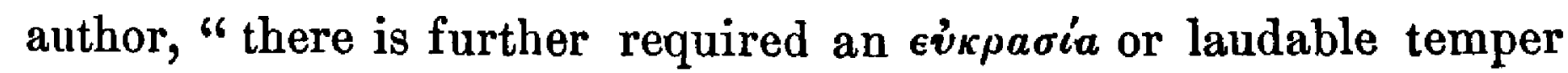
of the womb: for those whose wombs are either hot or cold, or moist or dry above measure, does not conceive, as saith Hippocrates. If, therefore, any of these things be wanting, we cannot hope for a lawful conception, but either there will be none at all, or a depraved and vicious, such as is of the moon calf or mola. For Nature rather endeavoureth an imperfect and depraved conception than none at all, because she is greedy of propagation, and diligent to maintain the perpetuity of the kind of things: whereupon, rather than she will do nothing, she will endeavour anything how imperfect soever."b

One of the most interesting "Exercitations" in "Harvey's Treatise on Generation" is that in which mention is made of this subject. Harvey observed that these substances are usually expelled in the early stage of the supposed pregnancy, and his ideas on the point appear to coincide with those of Hippocrates generally. ${ }^{\circ}$

a Hippocrates Translated, with Annotations. By Francis Adams, LL.D. Sydenham Society Edition. Vol. I., p. 197. London. 1849.

Mikpoeforpaфia. A Description of the Body of Man, together with the Controversies and Figures thereupon belonging. By Helkiah Crooke, Doctor in Physicke, Physitian to His Majesty. Folio. London. 1651. P. 219.

c Harvey on Generation. Exercitation the 56th, p. 420. Edition of 1653. 
From the time of Harvey down to the early part of this century, by the majority of obstetric authorities all vesicular growths found in utero were regarded as identical in character and development, with the true hydatids or acephalocysts discovered in other parts of the body. And obvious as are the differences between the thin-walled aggregated vesicular masses, resembling a bunch of white currants, resulting from the cystic proliferation of the placental chorionic villi of a blighted ovum, and the more densely laminated separate acephalocysts, it is not a little strange that these should have been confounded together even comparatively recently, and by an observer so generally accurate as the late Dr. Blundell, with whom, some twenty years ago, I had a correspondence on this question. Dr. Blundell says :- "Hydatids sometimes form in the ovum and (if I may be allowed the expression) devour it ; sometimes a part only being converted into their substance, so that they lie embedded and concealed in the placental structure ; sometimes the whole, or with the exception of a few vestiges being consumed, so that in place of the ovum nothing but these animalcules remains in the uterus." It may be observed, however, in explanation of the error into which former writers thus fell, that in some few instances true hydatids have been found within the uterus. Several years ago a case of this kind was published in the Lancet by Mr. Wilton, Surgeon to the Brighton Lying-in Institution:- "The patient was a woman aged thirty-seven, the mother of four children. She was admitted into hospital, suffering from uterine hæmorrhage and bearing-down pains. She died four days afterwards, and on examination the veins of the fundus were found varicose and congested; a large mass of hydatids was found protruding into the cavity of the uterus, and a large cluster, equal in size to a small tea-cup, was firmly adherent to the fundus. The lining membrane in the diseased part was entirely absent, and the masses of bydatids were firmly embedded in the structure of the uterus, the vessels being dissected into layers by them. Other masses were found between the mucous membrane and the structure

"Blundell's "Principles and Practice of Obstetric Melicine." Edited by Drs. Lee and Rogers, p. 250. 
of the uterus, and also in the right ovary, the substance of which was thus disorganised." And, more recently, the following suggestive case bearing on this question was related by Dr. Graily Hewitt:-"A young unmarried woman died with excessive enlargement of the abdomen, and on examination it proved the peritoneal cavity was beset with true hydatid cysts, which had originated primarily in the liver. These hydatid cysts were found attached to the uterus anteriorly as well as posteriorly, to the ovaries, to the walls of the pelvis-in fact, few portions of the peritoneal surface were without them. Had life been prolonged, the bursting of some of these cysts into the uterus, or into the vagina, was almost inevitable, and then the phenomena would have been presented of a young unmarried woman discharging true hydatids from the generative passages."

The first writer who maintained that all such moles are necessarily dependent on impregnation was Lamzweerde, who, in 1685, asserted that "Virgines non possunt concipere vel generare molam sine copula maris." The same author also declares that "Vidua non potest concipere molam virtute mariti defuncti relicta in utero, sine novo maris auxilio." And the modern theory on the origin of these growths in placental disease is a revival of the opinion of a Dutch writer of the seventeenth century (Ruysch), who says:"Haec recenta moles placentæ, penitus amittens genuinam suam indolem, quia est vasorum sanguineorum contextus, integro suo corpore mutatur in congeriem hydatidum." a The same view was supported by William Hunter in his Lectures in 1785 :- " $\mathrm{I}$ have seen," he says, "a placenta in the fourth month all degenerating into hydatids . . . the placenta and foetus being thus converted. They are generally the accompaniments, as also probably the results, of blighted and other diseased forms of eventually unproductive generation."

Modern Pathology of Vesicular Mole Pregnancy.-I need not occupy your time by any further allusion to the older doctrines on this subject, the more modern literature of which is probably

a Ruysch (Frederici)-Thesaurus Anatomicus. Pars Secunda, Tom. Primus, p. 47. Amstelodami : 1710. 
already familiar to the Academy. On the latter point I shall therefore merely add that the majority of recent authorities support the views concerning the pathology of vesicular mole or, as it is sometimes termed, myxoma of the chorionic villi, which are clearly expressed in the late Dr. Spiegelberg's "Text-book of Midwifery," an English version of the first volume of which has been lately published by the New Sydenham Society.

The vesicular or cystic mole, according to Spiegelberg, consists of a conglomerate of vesicles filled with pale, and for the most part clear, fluid, which are surrounded by the decidua, and in places project through it. They vary in size from a walnut to a millet seed, and are connected with each other by thin threadlike stalks.

The vesicles are degenerated chorionic villi. The degeneration consists of an abundant proliferation of the villi, and of hypertrophy of the internal mucoid matrix of the individual villus, the nuclei and cells increasing like the intercellular substance. In the fresh condition each vesicle has an epithelial covering; next to this comes the ground substance consisting of a closer tissue with small stellate cells, which are connected with the separate fibres of the tissue. The substance forming the stalks is very much like Wharton's jelly and consists of a firm mucous tissue, whose fibres are arranged longitudinally and pass imperceptibly into the homogeneous layer of the vesicles. The fluid contained in the latter shows a great similarity in composition to liquor amnii, but in addition to albumen it contains comparatively much mucin.

If the vesicular mole is formed at a very early date, as is the rule, the whole surface of the ovum undergoes degeneration, the embryo perishes, is disintegrated, and no remnant of it can be found. When the degeneration sets in after the placenta is formed, it is limited to the latter, although the whole surface of the ovum generally appears on superficial observation to be covered by the cysts ; the fotal cavity in this case is usually very distinct, and the remnant of the embryo or even the whole (atrophied) foetus is

- A Text Book of Midwifery. By the late Otto Spiegelberg. Translated from the German by J. B. Hurry, M.D. Now Sydenham Society, London. 1887. Vol. I., p. 451. 
present in it. Sometimes a simultaneous increase of the liquor amnii takes place. Degeneration of certain lobes of the placenta in the midst of healthy ones-partial myxoma-indeed in some places in different cotyledons, is also met with, and under such conditions no injury need result to the foetus.

The vesicular mole with a healthy foetus has several times been seen. The cause of the hyperplasia of the villi is unknown. It is undecided whether it indicates primary disease in the ovum, or depends on some irritation due to disease of the internal surface of the uterus, or to the maternal blood. That it is not a consequence of a very early death of the embryo, as is still often supposed, is clear, even though the villi may possibly continue to grow for some time after the death of the foetus. Such a supposition is contradicted by the rarity of vesicular moles, compared with the much more common early death of the embryo, by this pathological growth occurring after the formation of the placenta has begun, by the fact that atrophied embryos are met with in the moles, and by the cases of partial degeneration. The death of the fotus must therefore be looked upon as a consequence of the degeneration. The view which seeks to explain such degeneration by a morbid condition of the uterine mucous membrane (decidua) is supported by evidence of such disease obtained in different ways, and by the cases of partial degeneration. In those cases, however, in which no disease can be found in the uterus it becomes probable that the cause of the hyperplasia is to be sought for in an anomalous development of the allantois, all the more so as vesicular structures have also been observed in the umbilical cord. This view can also explain those cases of the degeneration of one twin ovum side by side with a normal second twin.

Vesicular Moles without Impregnation.-The question as to the probable occurrence of vesicular moles independently of impregnation in some instances, may be one of great importance in reference to the character of the patient. On this point Dr. Priestley has expressed a very decided opinion. This question, he says, came before a Court of Inquiry in India some years ago, and involved both the character of an unmarried woman and the reputation of 
a medical man whose opinion had impugned her chastity. The medical man collected the opinions of all the leading obstetricians in this country, and, although the balance of opinion greatly preponderated in favour of vesicular chorion being always the result of impregnation, there was at least one notable dissentient, who believed that the vesicles might be formed in the virgin uterus. We now know so accurately the way in which these vegetations are produced that doubt should no longer exist on the matter. With our present knowledge it would be just as reasonable to suppose that a child might be expelled from an unimpregnated uterus as a true vesicular chorion. ${ }^{\mathbf{a}}$ For my own part, loath as I am to differ from so eminent an authority on this subject as Dr. Priestley, and although I have not myself met with cases of vesicular mole which were not accompanied by the ordinary history and symptoms of pregnancy, I nevertheless agree with my old friend, the late Dr. Montgomery, that even yet " our knowledge on this point is by no means sufficiently precise, nor our collection of facts sufficiently extended to warrant us in pronouncing positively on the question, or asserting decidedly in a case of suspicion that a woman was pregnant merely because she discharged hydatids from the uterus." Nor can there be any doubt that several apparently well-authenticated cases that would seem to support the contrary opinion have been recorded by authorities whose veracity is unimpeachable. Thus Dr. Samuel Ashwell, in his treatise "On the Diseases of Women," speaking of the vesicular mole of the uterus, says:- "I have seen, at least, one example where they were the result of diseased action of the uterine lining membrane, independently of sexual intercourse."

Mr. Douglas Fox, Surgeon to the Derbyshire Infirmary, alsc reported the particulars of a case "in which a large mass of vesicular hydatids was expelled from the uterus of a maiden lady, where the hymen was unruptured, and of whose chastity there could not be a suspicion." Somewhat similar cases have been related by Dr. Hamilton, Dr. Fischer, and other writers.

- The Pathology of Intra-uterine Death. By Wm. O. Priestley, M.D. London. 1887. P. 112. 
It would be useless here to refer further to this question, or to review the many theories that have been suggested in explanation of such cases at different times. For my own part, I still adhere to the views I have maintained for many years on this subjectviz., firstly, that in the great majority of cases these growths originate in the cystic degeneration, or proliferation, of the exochorionic villi of a blighted ovum. Secondly, that cases, however, may also occur in which similar-looking products are found in the uterus, independently of impregnation. Thirdly, that the few well-authenticated and exceptional instances of the latter kind may probably be accounted for on the supposition of their origin in the ovary itself, and that the diseased ovum is thus primarily vitiated ere its arrival in the uterus, where it subsequently becomes adherent, and whence it continues to derive nutrition for its abnormal vitality and cystic proliferation or monstrous development, until, by its bulk, expulsive action is produced.

Treatment.-In the way of treatment I know of nothing that can be done to arrest the progress of the disease, but an attempt should always be made to prevent its recurrence by improving the general health of the patient by alteratives and ferruginous tonics, especially any of the saline chalybeate waters, such as Ems or Kissengen abroad, or Tunbridge Wells and Lisdoonvarna at home.

It has been recommended that we should bring on the expulsion of these vesicular moles as soon as they are discovered. This, however, is clearly wrong practice; for it is quite possible that only a portion of the placenta may be affected; or, as I have seen, the birth of a healthy living child may be immediately followed by the myxomatous placenta of a blighted twin conception. Hence, even if this disease could be diagnosticated at any time during the nine months of pregnancy, we should still let nature take her course, rather than by unnecessary interference run the risk of destroying a living foetus which experience has shown may possibly co-exis with the vesicular growth in utero. 